\title{
Trauma Induced External Inflammatory Root Resorption - A Case Report
}

\author{
Gudugunta Leneena ${ }^{1}$, Matada Basavarajaiah Jeevan ${ }^{2, *}$, Praffulla Mynampati ${ }^{3}$, Bhavana Vankayala ${ }^{4}$, Suresh Kandagal Veerabhadrappa ${ }^{5}$ \\ ${ }^{1}$ Faculty of Dentistry, Conservative and Endodontics, AIMST University, MALAYSIA. \\ 2Faculty of Dentistry, Oral Pathology, AIMST University, MALAYSIA. \\ ${ }^{3}$ Conservative and Endodontics, Dr. Sudha and Nageswara Rao Siddhartha Institute of Dental Sciences, Gannavaram, Andhra Pradesh, INDIA. \\ ${ }^{4}$ Conservative and Endodontics, Government Dental College and Hospital, Hyderabad, Telangana, INDIA. \\ ${ }^{5}$ Oral Medicine and Radiology, Faculty of Dentistry, Segi University, Kota Damansara, Selangor, MALAYSIA.
}

\begin{abstract}
Inflammatory root resorption is a serious complication of dental trauma, which leads to progressive loss of the root structure. It is challenging for a dental clinician to diagnose and plan the treatment for root resorption. This case report describes the diagnosis and treatment of a previously traumatized maxillary central incisor which was severely affected by inflammatory root resorption. This case was treated by conventional nonsurgical pulp space therapy. Calcium hydroxide dressing was given as an intra-canal medicament. The entire root was obturated with mineral trioxide aggregate. The radiographic follow up at 12 months showed arrest of root resorption and initiation of periapical healing in the absence of clinical symptoms and mobility. From the present case, it can be concluded that mineral trioxide aggregate obturation can be a viable option that can enhance the healing in
\end{abstract}

cases of severe inflammatory root resorption.

Key words: Trauma induced external inflammatory root resorption, Mineral trioxide aggregate, Regeneration, Non-surgical endodontic therapy.

Correspondence

Dr Jeevan Matada Basavarajaiah, MDS, Department of Oral Pathology, AIMST University, Jalan Bedong - Semeling, 08100 Bedong, Kedah Darul Aman, MALAYSIA.

Phone: +60 149033299

Email: mbjeevan@gmail.com

DOI: 10.5530/jyp.2018.10.109

\section{INTRODUCTION}

Root resorption is an important and common complication of traumatic dental injuries like intrusion, avulsion and luxation. Though the inflammation is present, usually, an intact tooth is resistant to resorption. ${ }^{1}$ If the protective layer of pre-cementum got damaged by trauma, inflammation of the periodontium or pulp may induce the root resorption. ${ }^{1-2}$ The extent of damage to the supporting tissues depends on the type and severity of the dento-alveolar trauma, which can lead to various types of resorptions. If the surface area of injured root surface is small and the inflammatory stimulus is transient or absent, the healing will be uneventful with reparative periodontal ligament and cementum. ${ }^{3}$ Conversely, if the affected area is large (i.e., $>20 \%$ of the root surface), healing will not be favourable, may lead to ankylosis and osseous replacement. ${ }^{4}$

When infection of the root canal is superimposed on trauma-induced resorption, the devastating process will be accentuated, leading to rapid loss of the tooth structure. ${ }^{5}$ This process is designated as "Infection-related root resorption" or "Inflammatory root resorption" ${ }^{6}$ and may exhibit as internal, external or combined internal and external lesions. ${ }^{2}$ Besides traumatic injuries, apical periodontitis, expanding tumours and cysts or heavy orthodontic forces may also initiate inflammatory root resorption. ${ }^{7}$ This case report presents the clinical and radiographic findings of a previously traumatized right maxillary central incisor, severely affected by inflammatory root resorption and the 12-months prognosis of treatment with MTA.

\section{CASE REPORT}

A 25 years old healthy male patient referred to Department of endodontics and Conservative dentistry Dr. Sudha and Nageswara Rao Siddhartha
Institute of Dental Sciences, Gannavaram, Andhra Pradesh, India. Patient had a chief complaint of discoloured tooth in upper front region since 5 years and he had a history of trauma 10 years before. Clinical extraoral examination revealed normal facial symmetry and competent lips. Intraoral examination revealed discoloured upper right central incisor (11) which was having Ellis class I fracture, Grade 1 mobility and tenderness on percussion. There was a labial sinus tract in relation to 11. Based on clinical features it was suspected as pulpal necrosis with periapical abscess and advised pulp vitality test and IOPA in relation to 11 . Vitality was negative. On radiographic examination, upper right central incisor presented with shortening of root with periapical radiolucency. Based on the patient's history and the clinical and radiographic examinations, it was diagnosed as trauma induced external inflammatory root resorption in relation to upper right central incisor.

\section{Treatment}

Tooth 11 was accessed and working length was determined $(11=16 \mathrm{~mm})$. Haemorrhage and exudates from the apical region of 11 was observed during the instrumentation. Bio-mechanical preparation was done till $140 \mathrm{k}$ - file. Calcium hydroxide dressing was given as an intracanal medicament. On second visit again calcium hydroxide dressing was initiated. During the same visit, the sinus tract disappeared, mobility has reduced and radiograph showed reduced periapical radiolucency. After drying the canal with paper points, MTA (White Pro-Root MTA; DentsplyMaillefer, Ballaigues, Switzerland) was manipulated according to the manufacturer's instructions. Manipulated MTA was placed in the root canal using a MTA delivery gun (Dentsply-Meillefer). Then, MTA was

This is an open access article distributed under the terms of the Creative Commons Attribution-NonCommercial-ShareAlike 4.0 License, which allows others to remix, tweak, and build upon the work non-commercially, as long as the author is credited and the new creations are licensed under the identical terms. 
gently condensed to the working length with the help of endodontic plugger. Until the root canal was filled with MTA the same procedure was repeated. A moistened cotton pellet was kept on the MTA and the cavity was restored temporarily with glass ionomer cement (GIC). After one week, the GIC was replaced with hybrid resin composite (TPH Spectrum DENTSPLY/DeTrey, Konstanz, Germany).

The radiographic follow up after 12 months of treatment demonstrated ceasing of the resorption, along with commencement of periapical healing in the absence of clinical symptoms. In same appointment, direct composite veneering was done to mask the discolouration.

\section{DISCUSSION}

Management of root resorption is challenging with unpredictable prognosis. Outcome depends on type of resorptive lesion, location of lesion and size of the lesion. The most common cause of root resorption is trauma especially in cases where the injury results in non-vitality and damage to the root surface in which dentinal tubules are exposed. ${ }^{8}$ Inflammation in the adjacent periodontal tissues is stimulated by bacteria, bacterial by-products and tissue breakdown products from within the root canal system and lead to severe and continuous inflammatory resorption of the root. ${ }^{9}$

Treatment of root resorption is dependent on the aetiology. If resorption is caused by pulpal necrosis and periodontal injury, nonsurgical root canal therapy should be done. Complete bio-mechanical preparation along with profuse irrigation is crucial in root canal disinfection. However, complete bacterial elimination is difficult to achieve. Intra-canal medicament may help to eliminate bacterial remnants in the root canal. ${ }^{10}$ Calcium hydroxide dressing as an intra-canal medicament in root canal disinfection was recommended by Andreasen. ${ }^{11}$

In the present case, entire root canal obturation with MTA was based on the following reasons. First, minimum $4 \mathrm{~mm}$ of MTA apical plug was required to afford optimum apical seal. ${ }^{12}$ Second, to prevent coronal leakage, a cervical barrier thickness of around $4 \mathrm{~mm}$ was necessary. ${ }^{13}$ As the root is very short, no additional space was left for placement of another obturating material (e.g., gutta-percha and sealer).

In clinical studies, it has been reported that obturation of the root canal with the MTA material favours the repair potential of the surrounding tissues as it can cause release of calcium ions through dentinal tubules into resorption sites. ${ }^{14}$ Furthermore, MTA induces the activity and expression of alkaline phosphatase in periodontal ligament fibroblasts. ${ }^{15}$ The hard tissue inductive effect of MTA has been confirmed in humans, particularly when used as apical plug in teeth with blunderbuss canals. ${ }^{16}$ At the molecular level, the induction of bone morphogenetic protein-2 (BMP-2) and transforming growth factor beta-1 (TGF $B-1)^{15}$ are the factors responsible for this favourable biologic effect. Stimulation of osteocalcin and subsequent bone growth, ${ }^{17}$ and stimulation of interleukin production, which leads to overgrowth of cementum. ${ }^{18}$

In the present case, non-vital bleaching was avoided to treat discolouration as it may lead to cervical root resorption. ${ }^{19}$ In recent years, direct and indirect laminate veneers have become treatment alternatives for patients with aesthetic problems of anterior teeth. The cost, social and time factors have to be considered in deciding between those two treatment options. ${ }^{20}$ Though there are still some disadvantages for direct veneering technique, especially discolorations and brittleness, they have also some advantages like minimal reduction, single appointment, low cost, repairable, no need of cementing medium and can avoid lab procedures. Therefore, composite laminate veneer restorations can be considered as one of the viable treatment choices in management of discoloured tooth. ${ }^{21}$

\section{CONCLUSION}

In the present case, though the crown root ratio could not be recovered an ideal level, the treatment outcome was considered successful, because the resorption was ceased and remained stable over the 12-months follow-up period. Furthermore, along with continued regeneration of the periapical tissues and the periodontal space, there were no clinical symptoms. Based on the clinical and radiographic findings, it can be concluded that using MTA as an obturating material can be a viable option in severe inflammatory root resorption cases.

\section{ACKNOWLEDGEMENT}

This study was supported by Disha Saraswathi and Mandava Ramesh Babu of Dr. Sudha and Nageswara Rao Siddhartha Institute of Dental Sciences, Gannavaram, Andhra Pradesh, India.

\section{CONFLICT OF INTEREST}

The authors declare no conflict of interest.

\section{ABBREVIATIONS}

MTA: Mineral trioxide aggregate; IOPA: Intra oral Periapical Radiograph; GIC: Glass Ionomer Cement; BMP-2: (Bone Morphogenetic Protein-2); TGF B-1:(Transforming Growth Factor Beta-1).

\section{REFERENCES}

1. Trope M. Root resorption of dental and traumatic origin: classification based on etiology. Pract Periodontics Aesthet Dent. 1998;10(4):515-22

2. Trope M, Chivian N, Sigurdsson A, Vann WF. Traumatic injuries. In: Cohen S, Burns RC, editors. Pathways of the pulp, $8^{\text {th }}$ edn. St Louis: Mosby. 2002;603-49.

3. Heithersay GS. Management of tooth resorption. Aust Dent J. 2007; 52(1Suppl):S105-21.

4. Sala M, Mendoza MA, Yañez VRM. Decoronation: An Alternative Treatment for Replacement Root Resorption. Case Rep Dent. 2017;2826948.

5. Andreasen JO, Bakland LK, Andreasen FM. Traumatic intrusion of permanent teeth. Part 3. A clinical study of the effect of treatment variables such as treatment delay, method of repositioning, type of splint, length of splinting and antibiotics on 140 teeth. Dent Traumatol. 2006;22(2):99-111.

6. Bendoraitiene E, Zemgulyte S, Borisovaite M. Reasonable Outcome of Avulsed Permanent Upper Incisor after Seven Years Follow-Up Period: a Case Report. J Oral Maxillofac Res. 2017;8(4):e6.

7. Gunraj MN. Dental root resorption. Oral Surg Oral Med Oral Pathol Oral Radiol Endod. 1999;88(6):647-53.

8. Ne RF, Witherspoon DE, Gutmann JL. Tooth resorption. Quintessence Int 199;30(1):9-25.

9. Bakland LK. Root resorption. Dent Clin North Am. 1992;36(2):491-507.

10. Larson TD. Causes and treatment of root resorption. Northwest Dent. 2010;89(3):45-7.

11. Andreasen JO. External root resorption: its implication in dental traumatology, paedodontics, periodontics, orthodontics and endodontics. Int Endod J. 1985;18(2):109-18.

12. Valois CR, Costa ED Jr. Influence of the thickness of mineral trioxide aggregate on sealing ability of root-end fillings in vitro. Oral Surg Oral Med Oral Pathol Oral Radiol Endod. 2004;97(1):108-11.

13. Barrieshi NKM, Hammad HM. Intracoronal sealing comparison of mineral trioxide aggregate and glass ionomer. Quintessence Int. 2005;36(7-8):539-45.

14. Ozdemir HO, Ozçelik B, Karabucak B, Cehreli ZC. Calcium ion diffusion from mineral trioxide aggregate through simulated root resorption defects. Dent Traumatol. 2008;24(1):70-3.

15. Guven G, Cehreli ZC, Ural A, Serdar MA, Basak F. Effect of mineral trioxideaggregate cements on transforming growth factor beta1 and bone morphogeneticprotein production by human fibroblasts in vitro. J Endod. 2007;33(4):447-50.

16. Torabinejad M, Chivian N. Clinical applications of mineral trioxide aggregate. 
J Endod. 1999;25(3):197-205.

17. Economides N, Pantelidou O, Kokkas A, Tziafas D. Short-term periradicular tissue response to mineral trioxide aggregate (MTA) as root-end filling material. Int Endod J. 2003;36(1):44-8.

18. Mitchell PJ, Pitt Ford TR, Torabinejad M, McDonald F. Osteoblast biocompatibility of mineral trioxide aggregate. Biomaterials. 1999;20(2):167-73.
19. Dahl JE, Pallesen U. Tooth bleaching--a critical review of the biological aspects. Crit Rev Oral Biol Med. 2003;14(4):292-304.

20. Sowmya K, Dwijendra KS, Pranitha V, Roy KK. Esthetic Rehabilitation with Direct Composite Veneering: A Report of 2 Cases. Case Rep Dent. 2017;7638153

21. Korkut B, Yanıkoulu F, Günday M. Direct composite laminate veneers: three casereports. J Dent Res Dent Clin Dent Prospects. 2013;7(2):105-11.

Article History: Submission Date : 21-06-2018; Revised Date : 17-07-2018; Acceptance Date : 06-08-2018.

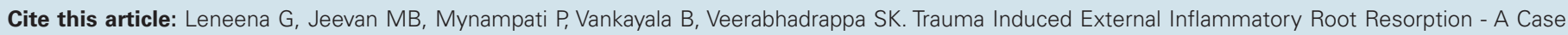
Report. J Young Pharm. 2018;10(4):494-6. 